К. ЛЭЭТС, Малле ШМИДТ,

Т. ВЯЛИМЯЭ, Т. КААЛ

\title{
ТЕЛОМЕРИЗАЦИЯ 1,3-ПЕНТАДИЕНА \\ С ИЗОБУТОКСИМЕТИЛХЛОРИДОМ
}

Несмотря на то, что реакция алкоксихлорметанов ( $\alpha$-хлорэфиров) с большинством алкенов и алкадиенов хорошо изучена ['], 1,3-пентадиену (пиперилену) посвящена лишь одна работа [2], где описано присоединение к нему метоксиметилхлорида и на основе экспериментальных данных сделан вывод, что в эфирном растворе с $\mathrm{ZnCl}_{2}$ присоединение идет только в 1,4-положении. Выход аддукта - 5-хлор-1-метокси-3-гексена $37 \%$. Получение исключительно 1,4-аддукта строго не доказано.

Нами с помощью ГЖХ и спектроскопии ЯМР ${ }^{13} \mathrm{C}$ установлено, что при теломеризации метоксиметилхлорида с 1,3-пентадиеном в условиях, описанных в [ $\left.{ }^{2}\right]$, продукты присоединения телогена в 1,2- и 1,4-положениях диена образуются в соотношении $1,4: 1[3]$.

Представляло интерес выяснить, как влияет увеличение радикала в алкоксиметилхлориде на соотношение продуктов 1,2- и 1,4-присоединения, а также на степень конверсии и выход моноаддукта.

Нами проведена реакция 1,3-пентадиена с изобутоксиметилхлоридом в растворе бензола. Испытано 5 катализаторов (см. таблицу). Продолжительность реакции 4 ч. Как видно из таблицы, лучшие результаты получены в присутствии $\mathrm{ZnCl}_{2}, \mathrm{BiCl}_{3}$ и $\mathrm{SnCl}_{4}$ : выход моноаддукта достигает $81-88 \%$ от общего количества теломера при степени конверсии $70,5-74,8 \%$. В присутствии $\mathrm{FeCl}_{3}$ и $\mathrm{SnCl}_{2}$ выход аддукта несколько ниже. В случае $\mathrm{FeCl}_{3}$ степень конверсии сравнительно низка (46,6\%), по всей вероятности, из-за малой концентрации катализатора. При

Теломеризация 1,3-пентадиена с изобутоксиметилхлоридом

\begin{tabular}{|c|c|c|c|c|c|c|}
\hline \multirow[b]{2}{*}{ Катализатор } & \multirow{2}{*}{ 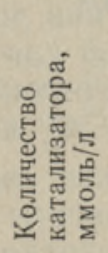 } & \multirow[b]{2}{*}{ 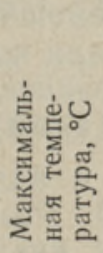 } & \multirow{2}{*}{ 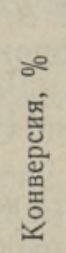 } & \multirow{2}{*}{ 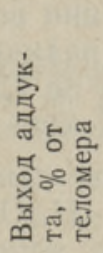 } & \multicolumn{2}{|c|}{$\begin{array}{c}\text { Содержание в } \\
\text { аддукте, \% }\end{array}$} \\
\hline & & & & & $\begin{array}{l}\text { продук- } \\
\text { та } 1,2- \\
\text { присое- } \\
\text { динения }\end{array}$ & $\begin{array}{l}\text { продук- } \\
\text { та 1,4- } \\
\text { присое- } \\
\text { динения }\end{array}$ \\
\hline $\begin{array}{l}\mathrm{SnCl}_{4} * \\
\mathrm{ZnCl}_{2} \\
\mathrm{BiCl}_{3} \\
\mathrm{FeCl}_{3} \\
\mathrm{SnCl}_{2}\end{array}$ & $\begin{array}{l}0,19 \\
7,3 \\
6,3 \\
0,62 \\
8,8\end{array}$ & $\begin{array}{l}30 \\
31 \\
30 \\
24 \\
32\end{array}$ & $\begin{array}{l}70,5 \\
74,3 \\
74,8 \\
46,6 \\
76,4\end{array}$ & $\begin{array}{l}81,0 \\
88,0 \\
85,5 \\
71,9 \\
68,4\end{array}$ & $\begin{array}{l}36,4 \\
34,0 \\
35,5 \\
33,0 \\
34,3\end{array}$ & $\begin{array}{l}37,0 \\
36,4 \\
36,2 \\
36,5 \\
35,1\end{array}$ \\
\hline
\end{tabular}

* В внде $10 \%$-ного раствора в дихлорэтане. В остальных случаях катализатор гетерогенный. 
бо́льших концентрациях, как найдено в случае изопрена [ $\left.{ }^{4}\right]$, реакция идет бурно с образованием в основном высокомолекулярных продуктов.

Состав аддукта (см. таблицу) зависит от применяемого катализатора очень незначительно. С помощью ГЖХ в аддукте идентифицировано два основных компонента (I и II) в приблизительно равных количествах с общим содержанием около $70 \%$. Вещество с меньшим временем удерживания, по всей вероятности, представляет собой продукт 1,2-присоединения, так как последний имеет более разветвленное строение. В меньшем количестве (по 9-12\%) в смеси найдено еще два изомера. Попытка разгонки изомерных изобутоксихлоргексенов не дает результатов из-за частичного дегидрохлорирования.

Спектроскопией ЯМР ${ }^{13} \mathrm{C}$ установлено, что присоединение изобутоксиметилхлорида в 1,2- и 1,4-положении диена происходит в равной степени. Оба продукта имеют $E$-конфигурацию. Химические сдвиги ядер ${ }^{13} \mathrm{C}$ в изомерах таковы (миллионные доли от тетраметилсилана (TMC)):

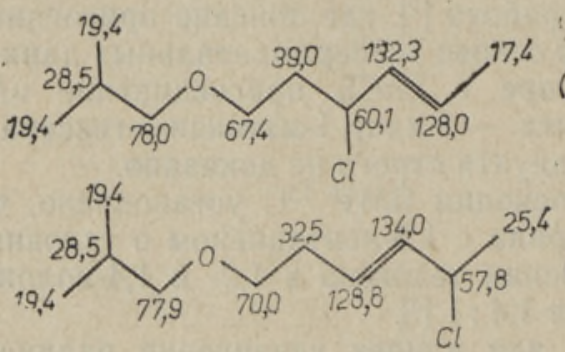

4-хлор-6-нзобутокси-2 (E)-гексен (1,2-прнсоединение)

Все эти данные показывают, что в рассматриваемом случае 1,2-аддукта образуется меньше, чем в реакции с метоксиметилхлоридом. Различия в степени конверсии и выходе моноаддукта незначительны.

\section{Экспериментальная часть}

Изобутоксиметилхлорид получили по методике [5] с выходом $60 \%$.

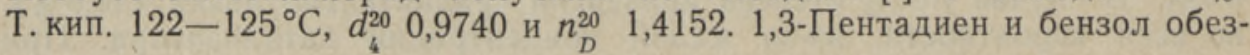
воживали кипячением над металлическим натрием и перегоняли.

В трехгорлую колбу $(0,25$ л), снабженную мешалкой, холодильником с хлоркальциевой трубкой и термометром, загружали 25 мл $(0,198$ моля) изобутоксиметилхлорида, 25 мл (0,25 моля) 1,3-пентадиена и 50 мл бензола. При охлаждении водой и перемешивании добавляли катализатор. Через 4 ч продукт реакции промывали водой для извлечения катализатора и высушивали на $\mathrm{CaCl}_{2}$. Растворитель отгоняли и продукт перегоняли в вакууме. Т. кип. $70-110^{\circ}(4 \mathrm{~mm}), n_{D}^{20}$ колебался в пределах $1,4433-1,4450$, содержание хлора в аддукте составляло $15,8-17,3 \%$ (вычислено для $\mathrm{C}_{10} \mathrm{H}_{19} \mathrm{OCl} 18,59 \%$ ). Результаты опытов приведены в таблице. Продукты теломеризации анализировали методом ГЖХ на хроматографе «Цвет 6-69A» с детектором ионизации в пламени. Колонка - стеклянная, капиллярная, длиной 50 м и внутренним диаметром 0,25 мм. Жидкая фаза - трицианоэтоксипропан; температура колонки $75^{\circ}$, испарителя $150^{\circ}$. Газ-носитель - аргон. Спектры ЯМР ${ }^{13} \mathrm{C}$ сняты на спектрометре AM-500 фирмы «Bruker» (ФРГ) при 125,76 МГц с полной развязкой от протонов. В качестве растворителя и источника сигнала для стабилизации магнитного поля использовали $\mathrm{CDCl}_{3}$. Химические сдвиги ядер углерода-13 измерены от внутреннего стандарта - TMC. 


\section{Выводы}

1. Показано, что в реакции теломеризации 1,3-пентадиена с изобутоксиметилхлоридом происходит в основном образование простого аддукта, имеющего $E$-конфигурацию.

2. При помощи ЯМР ${ }^{13} \mathrm{C}$ установлено, что присоединение элементов телогена происходит в равной степени как в 1,2-, так и в 1,4-положении таксогена.

\section{Л И Т Е Р А Т Р А}

1. Петров А. А., Генусов М. Л. Ионная теломеризация. Л., 1968, 103-134.

2. Шихмамедбекова А. З. Присоединение $\alpha$-хлордиметилового эфира к пиперилену. Ж. орган. хим., 1969, 5, вып. 11, 1941-1946.

3. Лээтс К. В., Шмидт М. И., Вялимяэ Т. К., Каал Т. А. О составе продукта теломеризации метоксиметилхлорида с 1,3-пентадиеном. - Ж. орган. хим., 1984, 20, вып. $7,1588-1589$.

4. Лээтс K., Каал T., Шмидт М., Кудрявцева $K$. Влияние природы катализатора на теломеризацию изопрена с $\alpha$-хлорметилизопропиловым эфиром. - Изв. АН ЭССР. Хим., 1980, 29, № 3, 232-234.

5. Поконова Ю. В. Галоидэфиры. М.-Л., 1966, 82.

\section{Ннститут химии \\ Академии наук Эстонской ССР}

Поступила в редакцию 29/III 1984

Ннститут химической и биологической физики

Академии наук Эстонской ССР

\section{K. LAATS, Malle SCHMIDT, T. VALIMAE, T. KAAL}

\section{1,3-PENTADIEENI JA ISOBUTOKSUMETUULKLORIIDI TELOMERISATSIOON}

Reaktsioonil tekib pōhiliselt monoadukt, kusjuures võrdselt moodustub 1,2- ja 1,4-liitumisprodukti. TMR ${ }^{13} \mathrm{C}$ andmeil on produktidel $E$-konfiguratsioon. Katalüsaatorina kasutati $\mathrm{SnCl}_{4}, \mathrm{ZnCl}_{2}, \mathrm{BiCl}_{3}, \mathrm{FeCl}_{3}$ ja $\mathrm{SnCl}_{2}$.

\section{K. LAATS, Malle SCHMIDT, T. VALIMAE, T. KAAL}

\section{TELOMERIZATION OF 1,3-PENTADIENE WITH ISOBUTOXY- METHYL CHLORIDE}

Mainly a monoadduct is formed in the title reaction; the amounts of the products of 1,2- and 1,4-addition are equal. The $\mathrm{NMR}{ }^{13} \mathrm{C}$ data show an $E$-configuration of the products. As catalysts $\mathrm{SnCl}_{4}, \mathrm{ZnCl}_{2}, \mathrm{BiCl}_{3}, \mathrm{FeCl}_{3}$ and $\mathrm{SnCl}_{2}$ were used. 